\title{
Association of PPAR Alpha Intron 7 G/C, PPAR Gamma 2 Pro12Ala, and C161T Polymorphisms with Serum Fetuin-A Concentrations
}

\author{
Bernadett Márkus, ${ }^{1}$ Krisztián Vörös, ${ }^{1}$ Dorina Supák, ${ }^{2}$ Zsolt Melczer, ${ }^{2}$ \\ Károly Cseh, ${ }^{3}$ and László Kalabay ${ }^{1}$ \\ ${ }^{1}$ Department of Family Medicine, Semmelweis University, Budapest, Hungary \\ ${ }^{2}$ 2nd Department of Obstetrics and Gynecology, Semmelweis University, Budapest, Hungary \\ ${ }^{3}$ Institute of Public Health, Semmelweis University, Budapest, Hungary \\ Correspondence should be addressed to László Kalabay; kalabay.laszlo@med.semmelweis-univ.hu
}

Received 3 March 2017; Revised 24 May 2017; Accepted 6 June 2017; Published 11 July 2017

Academic Editor: Marcin Baranowski

\begin{abstract}
Copyright ( 2017 Bernadett Márkus et al. This is an open access article distributed under the Creative Commons Attribution License, which permits unrestricted use, distribution, and reproduction in any medium, provided the original work is properly cited.
\end{abstract}

\begin{abstract}
Background. Both peroxisome activator proteins (PPARs) and fetuin-A play a role in lipid and glucose metabolism. Aims. We investigated whether PPAR $\alpha$ intron 7 G2468/C and PPAR $\gamma 2$ Prol2Ala and PPAR $\gamma$ exon 6 C161T polymorphisms are associated with serum fetuin-A concentrations. Patients and Methods. The PPAR $\alpha$ intron 7 G/C polymorphism was studied in cohort 1 (79 reference individuals, 165 postinfarction patients). The two PPAR $\gamma$ polymorphisms were investigated in cohort 2 (162 reference individuals, 165 postinfarction patients). Fetuin-A levels and PPAR polymorphisms were determined by radial immunodiffusion and polymerase chain reaction-restriction fragment length polymorphism techniques. Results. The C allele variant of PPAR $\alpha$ intron 7 G2467C was associated with higher fetuin-A levels $(p=0.018)$. Postinfarction status $(p=0.001)$, PPAR $\alpha$ intron 7 GG/GC/CC genotypes $(p=0.032)$, and the $C$ allele $(p=0.021)$ were the strongest determinants of fetuin-A concentration in a multiple regression model. Higher fetuin-A levels were associated with the Pro variant of PPAR $\gamma 2(p=0.047)$. Postinfarction status $(p=$ $0.041)$ and BMI $(p<0.001)$ but not PPAR $\gamma 2$ Pro were the strongest determinants of fetuin-A concentrations. PPAR $\gamma$ exon 6 C161T genotypes were not associated with fetuin-A levels. Conclusions. Fetuin-A was determined mainly by the PPAR $\alpha$ intron 7C allele and postinfarction status in cohort 1 and the BMI and postinfarction in cohort 2. The PPAR $\alpha$ intron 7C and PPAR $\gamma 2$ Pro variants are associated with fetuin-A levels.
\end{abstract}

\section{Introduction}

Human fetuin-A is a multifunctional hepatic glycoprotein that has been involved in the development of obesity [1$3]$, insulin resistance [4], metabolic syndrome [1, 5], type 2 diabetes [6-8], adipocyte dysfunction [9], and fatty liver [4].

Peroxisome proliferator-activated receptors (PPARs) are members of the nuclear hormone receptor superfamily of ligand-activated transcription factors. The PPAR subgroups $\operatorname{PPAR} \alpha, \operatorname{PPAR} \beta / \delta$, and $\operatorname{PPAR} \gamma(\gamma 1$ and $\gamma 2)$ play an important role in the pathogenesis of these processes, which has been extensively reviewed [10-12].

There are several observations suggesting a relationship between serum fetuin-A levels and activities of different
PPARs. For example, the direct inhibitory effect of pioglitazone on hepatic fetuin-A expression has been observed in rats [13] and in humans [14]; the former was reversed by GW9602, direct PPAR $\gamma$ inhibitor.

Polymorphisms of PPAR $\gamma$ and PPAR $\alpha$ have also been described and found to be associated with disorders of hyperlipidemia, glucose homeostasis, and diabetes. Thus the $\mathrm{C}$ allele of the PPAR $\alpha$ intron 7 polymorphism was found to be more frequent in patients with myocardial infarction and dyslipidemia [15]. The T allele of the PPAR $\gamma$ exon 6 C161T polymorphism was supposed to have protective role against coronary artery disease in Chinese population [16], whereas others found that this allele was associated with an increased 
risk for coronary heart disease [12]. The association between polymorphic variants of PPAR and serum fetuin-A levels, however, has not been investigated yet.

In our study, we aimed to investigate whether polymorphisms of PPAR $\gamma$ (PPAR $\gamma 2$ Pro12Ala and exon 6 C161T) and $\operatorname{PPAR} \alpha$ (intron 7 G2467C) are associated with or may affect serum fetuin-A levels in two cohorts.

\section{Patients and Methods}

Three-hundred and forty-two patients were originally involved in this study. Exclusion criteria were as follows: clinical or laboratory signs of acute vascular disease (myocardial infarction, stroke), acute infection, malignant tumor, hepatic disease, renal failure, immune suppression, severe medical or surgical conditions, and trauma. Finally, we had 327 patients (cohort 2) who had all comparable data (including successful genotyping for both PPAR $\gamma$ polymorphisms). We were able to perform successful PPAR $\alpha$ genotyping in a smaller number of patients (cohort 1 , $n=244)$. The genotyping success rate was greater than $99 \%$ in both cohorts. The genotypes were in the Hardy-Weinberg equilibrium.

$\operatorname{PPAR} \alpha$ polymorphism was studied in cohort 1 . This cohort comprised 244 individuals (120 men and 124 women, age: $60.1 \pm 11.2$ years, mean \pm SD). Cohort 1 consisted of 79 reference individuals (15 men, 64 women, age: $61.0 \pm 9.4$ years) and 165 patients surviving myocardial infarction (105 men, 60 women, age: $59.6 \pm 12.2$ years).

$\operatorname{PPAR} \gamma$ polymorphisms were studied in cohort 2 . This cohort consisted of 327 individuals (161 men, 166 women, age: $57.9 \pm 13.0$ years). This cohort consisted of 162 reference subjects (61 men, 101 women, age: $56.1 \pm 13.8$ years) and the same 165 postinfarction patients as in cohort 1 (105 men, 60 women, age: $59.6 \pm 12.2$ years).

Postinfarction patients had a history of STEMI myocardial infarction (6-24 months prior to the start of the study). Diabetes was diagnosed based on fasting plasma glucose $>$ $7.0 \mathrm{mmol} / \mathrm{l}$ or the 2 -hr OGTT > $11.1 \mathrm{mmol} / \mathrm{l}$. Patients with diabetes were treated with diet, metformin, and bedtime insulin.

All persons gave their informed consent prior to their inclusion in the study. The study was approved by the local Ethics Committee of the Károlyi Sándor Municipality Hospital.

2.1. Determination of PPAR Polymorphic Variants. The determination of the PPAR $\gamma$ and PPAR $\alpha$ variants was performed by PCR-RFLP technique.

The PPAR $\alpha$ G2467C intron 7 polymorphism (rs 4253778) was studied by PCR-RFLP technique, using a $5^{\prime}$ forward primer of ACA ATC ACT CCT TAA ATA TGG TGG and a $3^{\prime}$ reverse primer of AAG TAG GGA CAG ACA GGA CCA GTA. The PCR product was digested with Taq1 (New England Biolabs, Boston, MA, USA) resulting in one fragment of $266 \mathrm{bp}$ of the carriers of the wild-type allele and two fragments of 216 and $50 \mathrm{bp}$ in the carriers of the mutant allele (thermocycles $94^{\circ} \mathrm{C} 15 \mathrm{~min}, 30 \times 94^{\circ} \mathrm{C} 30 \mathrm{sec}, 50^{\circ} \mathrm{C}$ $20 \mathrm{sec}$, and $72^{\circ} \mathrm{C} 30 \mathrm{sec}$ ) [17].
For PPAR $\gamma$ Pro12Ala (rs 1801282) polymorphism, we used a $5^{\prime}$ forward primer of GCC AAT TCA AGC CCA GTC and a mutagenic $3^{\prime}$ reverse primer of GAT ATG TTT GCA GAC AGT GTA TCA GTG AAG GAA TCG CTT TCC G. The PCR product was digested with Bst U1 enzyme (New England Biolabs, Boston, MA, USA) resulting in one fragment of $270 \mathrm{bp}$ in the carriers of wild-type and two fragments of 227 and $43 \mathrm{bp}$ in carriers of mutant allele (thermocycles $95^{\circ} \mathrm{C}$ $15 \mathrm{~min}, 35 \times 94^{\circ} \mathrm{C} 30 \mathrm{sec}, 65^{\circ} \mathrm{C} 45 \mathrm{sec}$, and $72^{\circ} \mathrm{C} 1 \mathrm{~min}$ ) [18].

The exon 6 polymorphism C161T of PPAR $\gamma$ (rs 3856806) was investigated by PCR-RFLP technique using a $5^{\prime}$ forward primer of CAA GAC AAC CTG CTA CAA GC and a $3^{\prime}$ reverse primer of TCC TTG TAG ATC TCC TGC AG. The PCR product was digested with Pmll enzyme (New England Biolabs, Boston, MA, USA) resulting in two fragments of 120 and $80 \mathrm{bp}$ in carriers of the wild-type allele and only one fragment of $200 \mathrm{bp}$ in the carriers of the mutant allele (thermocycles $94^{\circ} \mathrm{C} 15 \mathrm{~min}, 30 \times 94^{\circ} \mathrm{C} 30 \mathrm{sec}, 56^{\circ} \mathrm{C} 30 \mathrm{sec}$, and $\left.72^{\circ} \mathrm{C} 30 \mathrm{sec}\right)[19]$.

2.2. Determination of Serum Fetuin-A Concentration. Serum fetuin-A concentrations were determined by radial immunodiffusion using the commercially available product (antifetuin-A, IgG fraction, Incstar, cat. number 81931, $13.7 \mathrm{mg} / \mathrm{ml}$, in a final concentration of $84 \mu \mathrm{l} / 11.5 \mathrm{mlgel}$ ), as previously described [20].

2.3. Determination of Insulin Resistance Parameters. Plasma glucose and insulin were determined by the routine $\mathrm{HK}$ G6P-DH and ELCIA methods, respectively. The Homeostasis Model Assessment-Insulin Resistance (HOMA-IR) model was calculated according to Matthews et al. [21].

2.4. Statistical Analysis. Statistical analysis was carried out using the SPSS v.21 statistical software (SPSS Inc., Chicago, IL, USA). Nonparametric methods, including the Bonferroni (Dunn) post hoc test, were used. $p$ values $<0.05$ were considered as significant.

\section{Results}

3.1. Subject Characteristics. The characteristics of the study participants are shown in Table 1.

Sixty-five per cent of the postinfarction patients received statins and $70 \%$ of them aspirin. Serum fetuin-A concentrations did not differ statistically between patients treated and not treated with these two medications $(687 \pm 122$ versus 636 $\pm 81 \mathrm{mg} / \mathrm{l}, p=0.204$ for statins and $665 \pm 0.120$ versus $672 \pm$ $124 \mathrm{mg} / \mathrm{l}, \mathrm{p}=0.795$ for aspirin, resp.).

3.2. PPAR $\alpha$ Intron $7 \mathrm{G} / \mathrm{C}$, PPAR $\gamma 2$ Prol2Ala, and PPAR $\gamma$ Exon 6 C161T Allele Distribution in Postinfarction Patients and Reference Individuals. The distribution of PPAR $\gamma$ and PPAR $\alpha$ alleles is shown in Table 2. PPAR $\gamma$ Pro12Ala and PPAR $\alpha$ intron $7 \mathrm{G} / \mathrm{C}$ alleles did not differ significantly between postinfarction patients and reference subjects. Postinfarction patients, however, had a significantly higher $\mathrm{T}$ allele frequency of the PPAR $\gamma$ C161T compared to reference subjects. 
TABLE 1: Subject characteristics.

\begin{tabular}{lcccc}
\hline & \multicolumn{2}{c}{$\begin{array}{c}\text { Cohort 1 } \\
(n=244)\end{array}$} & \multicolumn{2}{c}{$\begin{array}{c}\text { Cohort 2 } \\
(n=327)\end{array}$} \\
& $\begin{array}{c}\text { Reference individuals } \\
(n=79)\end{array}$ & $\begin{array}{c}\text { Postinfarction patients } \\
(n=165)\end{array}$ & $\begin{array}{c}\text { Reference individuals } \\
(n=162)\end{array}$ & $\begin{array}{c}\text { Postinfarction patients } \\
(n=165)\end{array}$ \\
\hline Gender (male/female) & $15 / 64$ & $105 / 60$ & $61 / 101$ & $105 / 60$ \\
Age (years, mean \pm SD) & $61.0 \pm 9.4$ & $59.6 \pm 12.2$ & $56.1 \pm 13.8$ & $59.6 \pm 12.2$ \\
BMI (kg/m $\left.{ }^{2}\right)$ & $24.1 \pm 1.6$ & $28.1 \pm 4.2^{* *}$ & $27.4 \pm 0.4$ & $28.1 \pm 4.2^{*}$ \\
Obesity (no/yes) & $68 / 11$ & $46 / 119^{* *}$ & $78 / 84$ & $46 / 119^{* *}$ \\
Diabetes status (no/yes) & $79 / 0$ & $112 / 53^{* *}$ & $139 / 23$ & $112 / 53^{* *}$ \\
HOMA-IR & $1.0 \pm 0.2$ & $6.2 \pm 4.6^{* *}$ & $1.5 \pm 1.5$ & $6.1 \pm 4.6^{* *}$ \\
\hline
\end{tabular}

${ }^{*} p<0.01$ and ${ }^{* *} p<0.001$, compared to reference individuals; BMI: body mass index; HOMA-IR: Homeostasis Model Assessment-Insulin Resistance; Mann-Whitney test.

TABLE 2: The PPAR $\alpha$ intron 7 G/C, PPAR $\gamma 2$ Pro12Ala, and PPAR $\gamma$ exon 6 C161T allele distribution among postinfarction patients and reference individuals.

\begin{tabular}{|c|c|c|c|c|c|}
\hline & Allelic frequency & $\chi^{2}$ & $\begin{array}{c}\mathrm{RR} \\
(95 \% \mathrm{CI}) \\
\end{array}$ & $\begin{array}{c}\text { OR } \\
(95 \% \mathrm{CI}) \\
\end{array}$ & $p$ \\
\hline \multicolumn{6}{|c|}{ PPAR $\alpha$ intron 7 G/C (rs4253778) } \\
\hline G & $\begin{array}{l}\text { P: } 0.8273 \\
\text { R: } 0.8165\end{array}$ & 0.0861 & $\begin{array}{c}1.013 \\
(0.9271-1.107)\end{array}$ & $\begin{array}{c}1.077 \\
(0.6571-1.764)\end{array}$ & 0.769 \\
\hline $\mathrm{C}$ & $\begin{array}{l}\text { P: } 0.1727 \\
\text { R: } 0.1835\end{array}$ & & & & \\
\hline \multicolumn{6}{|c|}{ PPAR 2 Pro12Ala (rs1801282) } \\
\hline Prol2 & $\begin{array}{l}\text { P: } 0.8618 \\
\text { R: } 0.8789\end{array}$ & 0.4279 & $\begin{array}{c}0.9804 \\
(0.9241-1.040)\end{array}$ & $\begin{array}{c}0.8583 \\
(0.5428-1.3570)\end{array}$ & 0.513 \\
\hline Ala12 & $\begin{array}{l}\text { P: } 0.1382 \\
\text { R: } 0.1211\end{array}$ & & & & \\
\hline \multicolumn{6}{|c|}{ PPARy exon 6 C161T (rs3856806) } \\
\hline $\mathrm{C}$ & $\begin{array}{l}\text { P: } 0.8735 \\
\text { R: } 0.9459\end{array}$ & 10.25 & $\begin{array}{c}0.9235 \\
(0.8799-0.9693)\end{array}$ & $\begin{array}{c}0.3953 \\
(0.2204-0.7091)\end{array}$ & 0.001 \\
\hline $\mathrm{T}$ & $\begin{array}{l}\text { P: } 0.1265 \\
\text { R: } 0.0541\end{array}$ & & & & \\
\hline
\end{tabular}

P: postinfarction patients; R: reference subjects; $p: \chi^{2}$ test.

\subsection{Analysis of Association between PPAR Intron 7 G2467C} Variants and Serum Fetuin-A Concentrations. Serum fetuinA levels of individuals with the CC genotype were higher than those of GG genotype (Table 3). In the dominant model ( $C$ versus non- $C$ nucleotide), individuals with the minor variant $C$ allele had significantly higher serum fetuinA concentrations than those with the non-C. In a recessive model ( $G$ versus non-G nucleotide), there was no difference between the two variants $(651 \pm 107 \mathrm{mg} / \mathrm{l}, n=238$ versus 662 $\pm 171 \mathrm{mg} / \mathrm{l}, n=6, p=0.702$ ).

Except for age, serum fetuin-A concentrations showed significant correlations with parameters listed in Table 4. Serum fetuin-A levels associated weakly but significantly with PPAR $\alpha$ intron 7 GG/GC/CC genotypes and the $\mathrm{C}$ allele but not with the $G$ allele. During partial correlation analysis, however, the correlation between fetuin-A concentrations and PPAR $\alpha$ intron 7 GG/GC/CC genotype lost significance when corrected for BMI $(r=0.100, p=0.125)$, diabetes status $(r=0.108, p=0.092)$, HOMA-IR $(r=0.116$, $p=0.072)$, and postinfarction status $(r=0.122, p=$ 0.058). Correlation between fetuin-A levels and the PPAR $\alpha$ intron 7C allele also became insignificant when corrected for BMI $(r=0.107, p=0.095)$, diabetes status $(r=0.115$, $p=0.072)$, and HOMA-IR $(r=0.123, p=0.056)$ but remained significant after correction for postinfarction status $(r=0.131, p=0.041)$.

The results of the univariate linear regression analysis between independent variables (predictors) and serum fetuin-A concentration (dependent variable) are shown in Table 5. Serum fetuin-A levels showed weak but statistically significant data with all investigated potential predictors, including PPAR $\alpha$ intron 7 G/C genotypes and the C allele but not with age. Thus age was excluded from further analysis.

Next we investigated whether PPAR $\alpha$ intron 7 G/C genotype and the $\mathrm{C}$ allele may determine serum fetuinA concentration in a multiple regression model (Table 6). In the model containing all independent parameters, we investigated the PPAR $\alpha$ intron 7 GG/GC/CC genotype and 
TABLE 3: Serum fetuin-A concentrations in individuals with different PPAR $\alpha$ intron 7 G2467C SNP polymorphisms and alleles.

(a) PPAR $\alpha$ intron 7 G2467C polymorphisms

\begin{tabular}{lccccc}
\hline \multicolumn{1}{c}{ GG } & \multicolumn{2}{c}{ GC } & \multicolumn{2}{c}{ CC } & \\
Fetuin-A mg/l & $n$ & Fetuin-A mg/l & $n$ & Fetuin-A mg/l & $n$ \\
\hline $641 \pm 150$ & 164 & $671 \pm 110$ & 74 & $662 \pm 170$ & 6 \\
\hline
\end{tabular}

(b) PPAR $\alpha$ intron 7 G2467C alleles

\begin{tabular}{lcccc}
\hline & C allele & & non-C & \\
Fetuin-A mg/l & $n$ & Fetuin-A mg/l & $p$ & $p$ \\
\hline $670 \pm 114$ & 80 & $641 \pm 105$ & 164 & $0.018^{\S}$ \\
\hline
\end{tabular}

${ }^{\#}$ Kruskal-Wallis test; ${ }^{\S}$ Mann-Whitney test.

TABLE 4: Correlation between serum fetuin-A and investigated parameters $(n=244)$.

\begin{tabular}{lcc}
\hline Parameter & Correlation coefficient & $p$ \\
\hline BMI & 0.167 & 0.009 \\
Diabetes status (no/yes) & 0.133 & 0.038 \\
HOMA-IR & 0.205 & 0.001 \\
Age & -0.109 & 0.188 \\
Gender & -0.168 & 0.017 \\
Postinfarction status (no/yes) & 0.277 & $<0.001$ \\
PPAR $\alpha$ GG/GC/CC & 0.144 & 0.025 \\
PPAR $\alpha$ C allele & 0.151 & 0.018 \\
PPAR $\alpha$ G allele & 0.025 & 0.700 \\
\hline
\end{tabular}

BMI: body mass index; HOMA-IR: Homeostasis Model Assessment-Insulin Resistance; Spearman correlation.

TABLE 5: Univariate regression analysis between serum fetuin-A concentrations and metabolic parameters $(n=244)$.

\begin{tabular}{lcc}
\hline Predictor & Standardized $\beta$ & $p$ \\
\hline BMI & 0.146 & 0.023 \\
Diabetes status (no/yes) & 0.136 & 0.034 \\
HOMA-IR & 0.163 & 0.011 \\
Postinfarction status (no/yes) & 0.212 & 0.001 \\
Age & -0.137 & 0.098 \\
Gender & -0.149 & 0.027 \\
PPAR $\alpha$ GG/GC/CC & 0.131 & 0.042 \\
PPAR $\alpha$ C allele & 0.140 & 0.029 \\
\hline
\end{tabular}

BMI: body mass index; HOMA-IR: Homeostasis Model Assessment-Insulin Resistance.

the $\mathrm{C}$ allele were the only statistically significant predictors of serum fetuin-A levels. In a backward stepwise regression model, the postinfarction status, the PPAR $\alpha$ intron 7 GG/GC/CC genotypes, and the $\mathrm{C}$ allele proved to be the strongest determinants of fetuin-A concentration.

3.4. Analysis of Association between PPAR 2 Pro12Ala Variants and Serum Fetuin-A Concentrations. Patients with Pro/Pro and Pro/Ala genotype had significantly higher serum fetuin-A concentrations than those with the Ala/Ala genotype (Pro/Pro: $681 \pm 131 \mathrm{mg} / \mathrm{l}, n=247$, Pro/Ala: $706 \pm$
$131 \mathrm{mg} / \mathrm{l}, n=75$, and Ala/Ala: $565 \pm 116 \mathrm{mg} / \mathrm{l}, n=5$, $p=0.043$, Kruskal-Wallis test). In the recessive model (Pro versus non-Pro), the fetuin-A level associated with the allele determining Pro exceeded that of the non-Pro variant (687 \pm $131 \mathrm{mg} / \mathrm{l}, n=322$ versus $565 \pm 116 \mathrm{mg} / \mathrm{l}, n=5, p=0.047$, Mann-Whitney test). Fetuin-A concentrations did not differ in the recessive model (Ala versus non-Ala) $(698 \pm 143 \mathrm{mg} / \mathrm{l}$, $n=80$ versus $681 \pm 131 \mathrm{mg} / \mathrm{l}, n=247, p=0.287)$.

Serum fetuin-A concentration was significantly associated with BMI, HOMA-IR, gender, and the Pro allele but not with the diabetes and postinfarction status, PPAR $\gamma$ Pro/Pro, Pro/Ala, and Ala/Ala genotypes or the Ala allele (Table 7). Thus these two latter parameters were left out from further analysis. The correlation between fetuin-A concentration and the Pro allele was lost following correction for BMI and gender but not with HOMA-IR (Table 8).

Univariate regression analysis showed that serum fetuinA (dependent variable) weakly but significantly correlated with BMI and the PPAR $\gamma$ Pro allele (independent variable, Table 9). This latter independent variable lost its predictor role when BMI was included in the regression model.

In the multiple backward stepwise regression model, postinfarction status $(\beta=0.111, p=0.041)$ and $\mathrm{BMI}(\beta=$ $0.426, p<0.001)$ proved to be the strongest determinants of fetuin-A concentrations.

3.5. Analysis of Association between PPAR $\gamma$ Exon 6 C161T Variants and Serum Fetuin-A Concentrations. We found no significant differences among serum fetuin-A concentrations of individuals with different PPAR $\gamma$ exon 6 C161T genotypes, nor between the $\mathrm{C}$ and non- $\mathrm{C}$ or $\mathrm{T}$ and non- $\mathrm{T}$ groups (Table 10). Fetuin-A levels did not correlate with the PPAR $\gamma$ C161T genotypes, $\mathrm{C}$, and $\mathrm{T}$ alleles, either (data not shown).

There were 3 minor variant homozygotes (TT) in the postinfarction but none in the reference group. Thus the genotype distribution of postinfarction patients markedly differed from that of reference individuals (CC/CT/TT: $130 / 37 / 3$ versus $140 / 17 / 0, p=0.006$ ). The $\mathrm{T}$ allele was significantly more frequent among postinfarction patients compared to reference group $(40 / 170=23.5 \%$ versus $17 / 157=$ $10.8 \%, p=0.002)$. Accordingly, postinfarction patients with the CC genotype had lower fetuin-A levels than reference subjects $(668 \pm 113 \mathrm{mg} / \mathrm{l}, n=130$ versus $710 \pm 146 \mathrm{mg} / \mathrm{l}$, $n=140, p=0.037)$. 
TABLE 6: Multiple regression analysis of PPAR $\alpha$ intron 7 G/C genotypes and C allele and serum fetuin-A concentration $(n=244)$.

\begin{tabular}{|c|c|c|c|c|}
\hline \multirow{2}{*}{ Predictor } & \multicolumn{2}{|c|}{ PPAR $\alpha$ intron 7 GG/GC/GG } & \multicolumn{2}{|c|}{ PPAR $\alpha$ intron $7 \mathrm{C}$ allele } \\
\hline & Standardized $\beta$ & $p$ & Standardized $\beta$ & $p$ \\
\hline \multicolumn{5}{|c|}{ All predictors included } \\
\hline BMI & 0.027 & 0.708 & -0.024 & 0.743 \\
\hline Diabetes status (no/yes) & 0.054 & 0.474 & 0.045 & 0.551 \\
\hline HOMA-IR & 0.037 & 0.651 & 0.035 & 0.666 \\
\hline Postinfarction status (no/yes) & 0.130 & 0.127 & 0.132 & 0.121 \\
\hline Gender & -0.079 & 0.260 & -0.083 & 0.242 \\
\hline \multirow[t]{2}{*}{ PPAR $\alpha$ intron 7 genetics ${ }^{\#}$} & 0.134 & 0.036 & 0.144 & 0.024 \\
\hline & \multicolumn{2}{|c|}{ Model fit: $p=0.006$} & \multicolumn{2}{|c|}{ Model fit: $p=0.005$} \\
\hline \multicolumn{5}{|c|}{ Stepwise backward regression } \\
\hline Postinfarction status (no/yes) & 0.214 & 0.001 & 0.215 & 0.001 \\
\hline \multirow[t]{2}{*}{ PPAR $\alpha$ intron 7 genetics $^{\#}$} & 0.135 & 0.032 & 0.144 & 0.021 \\
\hline & \multicolumn{2}{|c|}{ Model fit: $p<0.001$} & \multicolumn{2}{|c|}{ Model fit: $p<0.001$} \\
\hline
\end{tabular}

\# Regression parameters of the PPAR $\alpha$ intron 7 GG/GC/GG genotypes are indicated in the second and the third and those of the PPAR $\alpha$ intron 7 C allele in the fourth and fifth columns of the table, respectively; BMI: body mass index; HOMA-IR: Homeostasis Model Assessment-Insulin Resistance.

TABLE 7: Correlation between serum fetuin-A and investigated parameters $(n=327)$.

\begin{tabular}{lcc}
\hline Parameter & Correlation coefficient & $p$ \\
\hline BMI & 0.426 & $<0.001$ \\
Diabetes status (no/yes) & 0.102 & 0.064 \\
HOMA-IR & 0.129 & 0.027 \\
Gender & -0.178 & 0.008 \\
$\begin{array}{l}\text { Postinfarction status } \\
\text { (no/yes) }\end{array}$ & 0.098 & 0.078 \\
PPAR $\gamma$ Pro/Pro, Pro/Ala, & & \\
and Ala/Ala & 0.050 & 0.365 \\
PPAR $\gamma$ Pro allele & 0.130 & 0.018 \\
PPAR $\gamma$ Ala allele & 0.052 & 0.349 \\
\hline
\end{tabular}

BMI: body mass index HOMA-IR: Homeostasis Model Assessment-Insulin Resistance; Spearman correlation.

TABLE 8: Partial correlation between serum fetuin-A concentrations and PPAR $\gamma$ Pro allele $(n=327)$.

\begin{tabular}{lcc}
\hline Corrected for & Correlation coefficient & $p$ \\
\hline Uncorrected & 0.130 & 0.018 \\
BMI & 0.069 & 0.215 \\
HOMA-IR & 0.129 & 0.027 \\
Gender & 0.129 & 0.055 \\
\hline
\end{tabular}

\section{Discussion}

In our study, we investigated whether PPAR $\alpha$ intron $7 \mathrm{G} / \mathrm{C}$, PPAR 22 Pro12Ala, and PPAR $\gamma$ C161T variants are associated with serum fetuin-A concentration. Since subjects in our groups had several parameters that are known to affect fetuinA levels such as age, gender, BMI, parameters of insulin resistance (diabetes status, HOMA-IR), and postinfarction status [22], we chose regression model to estimate the impact of these variables.
TABLE 9: Univariate regression analysis between serum fetuin-A concentrations and predictor parameters $(n=327)$.

\begin{tabular}{lcc}
\hline Predictor & Standardized $\beta$ & $p$ \\
\hline BMI & 0.520 & $<0.001$ \\
\hline Diabetes status (no/yes) & 0.065 & 0.239 \\
\hline HOMA-IR & 0.059 & 0.291 \\
\hline Postinfarction status (no/yes) & 0.137 & 0.013 \\
\hline PPAR $\gamma$ Pro allele & 0.127 & 0.022 \\
\hline PPAR $\gamma$ Pro allele & 0.059 & 0.215 \\
+ BMI & 0.512 & $<0.001$ \\
\hline BMI: body mass index; HOMA-IR: Homeostasis Model Assessment-Insulin \\
Resistance.
\end{tabular}

PPAR $\alpha$ has been termed as a lipid sensor and is involved in microsomal $\omega$-oxidation and mitochondrial and peroxisomal $\beta$-oxidation resulting in energy burning and reduced fat storage [11]. The minor variant of the PPAR $\alpha$ intron 7C has been considered to have a decreased activity compared to $\mathrm{G}$, the major variant. The $\mathrm{C}$ haplotype promotes the early development of type 2 diabetes [17] and is more frequent among postinfarction patients $[12,15]$. Doney et al. have found that the risk of myocardial infarction is higher in the presence of the $\mathrm{C}$ allele [23]. We also have found that the $\mathrm{C}$ allele is associated with higher fetuin-A levels and the multiple regression revealed that fetuin-A levels are strongly determined by the postinfarction status and remarkably by the PPAR $\alpha$ intron 7 G/C polymorphism, as well. Although the $\mathrm{C}$ allele was not more frequent among our postinfarction patients, the higher fetuin- $\mathrm{A}$ concentration may also have deleterious effects in them. Elevated fetuin-A concentration is a marker of fatty liver, characterized by decreased $\beta$-oxidation of fatty acids [4].

Fetuin-A is synthesized almost exclusively by the hepatocytes in adults [24] and the PPAR $\alpha$ is mainly expressed in the liver, as well. Fetuin-A is known as an endogenous ligand 
TABLE 10: Serum fetuin-A concentrations in individuals with different PPAR $\gamma$ exon 6 C161T polymorphisms and alleles $(n=327)$.

(a) PPAR exon 6 C161T polymorphisms

\begin{tabular}{lccccc}
\hline \multicolumn{1}{c}{ CC } & \multicolumn{2}{c}{ CT } & \multicolumn{2}{c}{ TT } & $p$ \\
Fetuin-A mg/l & $n$ & Fetuin-A mg/l & $n$ & Fetuin-A mg/l & $n$ \\
\hline $690 \pm 133$ & 270 & $661 \pm 125$ & 54 & $641 \pm 104$ & 3 \\
\hline
\end{tabular}

(b) PPAR $\gamma$ exon 6 C161T Ala Allele

\begin{tabular}{|c|c|c|c|c|}
\hline Fetuin-A mg/l & $n$ & Fetuin-A mg/l & $n$ & $p$ \\
\hline & \multicolumn{4}{|c|}{ non-C } \\
\hline $685 \pm 132$ & 324 & $641 \pm 104$ & 3 & $0.674^{\S}$ \\
\hline & \multicolumn{4}{|c|}{ non-T } \\
\hline $659 \pm 123$ & 57 & $690 \pm 133$ & 270 & $0.138^{\S}$ \\
\hline
\end{tabular}

${ }^{\#}$ Kruskal-Wallis test; ${ }^{\S}$ Mann-Whitney test.

that binds to free fatty acids and functions as an endogenous ligand for the Toll-like receptor TLR-4 thereby linking metabolic diseases (hyperlipidemia, insulin resistance) and subclinical inflammation [25]. This "missing link" character of fetuin-A has been further supported by the clinical studies of Stefan and Häring [26]. These findings are in line with our observation that postinfarction status, an endpoint of subclinical inflammation, and PPAR $\alpha$ intron 7C allele were the strongest determinants of fetuin-A in our subjects.

Compared to Ala metabolically disadvantageous characteristics are attributed to the Pro variant of PPAR $\gamma 2$ Pro12Ala [27]. Indeed, we found only the Pro allele among individuals with BMI over $25 \mathrm{~kg} / \mathrm{m}^{2}$ and only lean (BMI $\leq 25 \mathrm{~kg} / \mathrm{m}^{2}$ ) subjects had the Ala/Ala homozygous variant. Nevertheless, even among individuals with the Ala variant, obesity was associated with higher fetuin-A levels compared to lean ones. Patients with diabetes had higher fetuin-A levels, the difference being significant in Pro/Pro major allele homozygotes $(704 \pm 124 \mathrm{mg} / \mathrm{l}, n=64$ versus $673 \pm 132 \mathrm{mg} / \mathrm{l}$, $n=183, p=0.020)$. Since fetuin-A is known to be the natural inhibitor of the insulin receptor tyrosine kinase, the Pro allele may convey increased insulin resistance. Indeed, we found minor variant Ala to be more frequent among nondiabetics $(68 / 251=27.1 \%)$ compared to diabetics $(12 / 76$ $=15.8 \%, p=0.044)$. This finding is in accordance with that of Vergotine, who observed that the Pro allele increases insulin resistance, along with IRS1Gly972 [28]. Conversely, the minor allele Ala seemed to be protective in Iranian and Chinese populations $[29,30]$. In our model, however, the relationship of fetuin-A levels with BMI and postinfarction status was much stronger than the one with insulin resistance (diabetes status or HOMA). The Pro allele was associated with higher fetuin-A in the nondiabetic group, as well, which is reflected by the weak correlation with diabetes status and HOMA-IR. Given the property of fetuin-A to increase insulin resistance, its weak association with the Pro allele can contribute to the deleterious effects of this allele.

Analysis of the effect of the PPAR $\gamma$ C161T variants on serum fetuin-A concentrations yielded the least consistent results. We had 3 minor homozygotes (TT) among the postinfarction patients but not among the reference subjects.
This finding is in accord with the observation of Qian et al., who found that coronary heart disease was not associated with the T-carrier state but these individuals had higher risk for acute coronary heart syndrome [12]. Wu et al. found mild protective effect of the $\mathrm{T}$ allele only in the Chinese but not in other populations [16]. We found no marked associations of C161T genotypes and alleles neither in postinfarction patients nor in the reference group, and not during the analysis of nonobese, nondiabetic individuals. This suggests that the C161T has the weakest association with fetuin-A levels out of the three PPAR polymorphisms we studied. Since PPAR $\gamma$ is expressed mainly in the fat tissue, its association with the levels of the liver secretory protein fetuin-A cannot be as close as that of PPAR $\alpha$.

Although not yet entirely clarified, several observations suggest the molecular basis of the association between PPAR variants and fetuin-A synthesis. The PPAR $\alpha$ agonist fibrates decrease fetuin-A expression in obese patients with or without type 2 diabetes mellitus [31]. The PPAR $\gamma$ agonist pioglitazone strongly inhibits fetuin-A expression [14]. The upregulation of both $\operatorname{PPAR} \alpha$ and $\operatorname{PPAR} \gamma$ results in the downregulation of fetuin-A and $\mathrm{NF} \kappa \mathrm{B}$ and upregulation of the AMPK kinase activities. Palmitate, the oxidation of which is highly induced by $\operatorname{PPAR} \alpha$, has been shown to stimulate $\mathrm{NF} \kappa \mathrm{B}$ binding to the fetuin-A promoter [9]. Thus a less functional variant of PPAR $\alpha$ could finally result in enhanced fetuin-A expression.

Our study has its limitations. First, the sample size is not big enough to allow for analysis of a comparable number of minor variants. Second, our cohorts were not controlled for environmental factors and prescribed medication and dietary saturated and polyunsaturated fat as it has been suggested [32].

\section{Conclusion}

In summary, our results indicate a relatively close relationship between PPAR $\alpha$ intron 7 G/C and PPAR $\gamma 2$ Prol2Ala variants and serum fetuin-A concentrations reflecting higher levels in the presence of the $\mathrm{C}$ allele of the former and the Pro allele of the latter one. It is very likely that these associations 
are obscured by obesity and/or diabetes. Larger scale studies are needed to further determine the biological and clinical significance of the PPAR polymorphisms on fetuin-A levels.

\section{Conflicts of Interest}

The authors declare that there are no conflicts of interest regarding the publication of this paper.

\section{Authors' Contributions}

Bernadett Márkus was responsible for the preparation of the manuscript; Krisztián Vörös was responsible for the statistical analysis; Dorina Supák and Zsolt Melczer were responsible for patient and data management; Károly Cseh was responsible for the determination of PPAR polymorphisms and critical review of the manuscript; László Kalabay was responsible for conceiving the idea of the study and critical review of the manuscript.

\section{Acknowledgments}

The authors thank V. M. Nagyne for the determination of serum fetuin-A concentration. This work was supported by grant of the Hungarian Ministry of Health ETT 368/2009.

\section{References}

[1] T. Reinehr and C. L. Roth, "Fetuin-A and its relation to metabolic syndrome and fatty liver disease in obese children before and after weight loss," Journal of Clinical Endocrinology and Metabolism, vol. 93, no. 11, pp. 4479-4485, 2008.

[2] C. Lavebratt, S. Wahlqvist, L. Nordfors, J. Hoffstedt, and P. Arner, "AHSG gene variant is associated with leanness among Swedish men," Human Genetics, vol. 117, no. 1, pp. 54-60, 2005.

[3] P. Suchanek, I. Kralova-Lesna, R. Poledne, V. Lanska, and J. A. Hubacek, "An AHSG gene variant modulates basal metabolic rate and body composition development after a short-time lifestyle intervention," Neuroendocrinology Letters, vol. 32, no. 2, pp. 32-36, 2011.

[4] N. Stefan, A. M. Hennige, H. Staiger et al., " $\alpha 2$-HeremansSchmid glycoprotein/fetuin-A is associated with insulin resistance and fat accumulation in the liver in humans," Diabetes Care, vol. 29, no. 4, pp. 853-857, 2006.

[5] J. H. Ix, M. G. Shlipak, V. M. Brandenburg, S. Ali, M. Ketteler, and M. A. Whooley, "Association between human fetuin-A and the metabolic syndrome: Data from the heart and soul study," Circulation, vol. 113, no. 14, pp. 1760-1767, 2006.

[6] N. Stefan, A. Fritsche, C. Weikert et al., "Plasma fetuin-A levels and the risk of type 2 diabetes," Diabetes, vol. 57, no. 10, pp. 27622767, 2008.

[7] N. Stefan, H.-U. Häring, and M. B. Schulze, "Association of fetuin-A level and diabetes risk," JAMA - Journal of the American Medical Association, vol. 300, no. 19, p. 2247, 2008.

[8] J. H. Ix, C. L. Wassel, A. M. Kanaya et al., "Fetuin-A and incident diabetes mellitus in older persons," JAMA - Journal of the American Medical Association, vol. 300, no. 2, pp. 182-188, 2008.

[9] S. Dasgupta, S. Bhattacharya, A. Biswas et al., "NF- $\kappa$ B mediates lipid-induced fetuin-A expression in hepatocytes that impairs adipocyte function effecting insulin resistance," Biochemical Journal, vol. 429, no. 3, pp. 451-462, 2010.

[10] C. P. Dong, L. He, J. N. Li, F. Ye, M. He, and Y. Wang, "Association of the Pro12Ala and C1431T polymorphism of the PPAR gamma2 gene and their haplotypes with obesity and type 2 diabetes," Chinese Journal of Medical Genetics, vol. 25, no. 4, pp. 447-451, 2008.

[11] B. Grygiel-Górniak, "Peroxisome proliferator-activated receptors and their ligands: nutritional and clinical implications-a review," Nutrition Journal, vol. 13, article 17, 2014.

[12] Y. Qian, P. Li, J. Zhang et al., "Association between peroxisome proliferator-activated receptor-alpha, delta, and gamma polymorphisms and risk of coronary heart disease: A case-control study and meta-analysis," Medicine (United States), vol. 95, no. 32, Article ID e4299, 2016.

[13] A. Ochi, K. Mori, M. Emoto et al., "Direct inhibitory effects of pioglitazone on hepatic fetuin-A expression," PLoS ONE, vol. 9, no. 2, Article ID e88704, 2014.

[14] K. Mori, M. Emoto, T. Araki et al., "Effects of pioglitazone on serum fetuin-A levels in patients with type 2 diabetes mellitus," Metabolism: Clinical and Experimental, vol. 57, no. 9, pp. 12481252,2008

[15] S. Purushothaman, V. K. Ajitkumar, and R. Renuka Nair, "Association of PPARalpha Intron 7 Polymorphism with Coronary Artery Disease: A Cross-Sectional Study," ISRN Cardiology, vol. 2011, Article ID 816025, 2011.

[16] Z. Wu, Y. Lou, W. Jin, Y. Liu, L. Lu, and G. Lu, “The C161T polymorphism in the peroxisome proliferator-activated receptor gamma gene (PPAR $\gamma)$ is associated with risk of coronary artery disease: a meta-analysis," Molecular Biology Reports, vol. 40, no. 4, pp. 3101-3112, 2013.

[17] D. M. Flavell, H. Ireland, J. W. Stephens et al., "Peroxisome proliferator-activated receptor $\alpha$ gene variation influences age of onset and progression of type 2 diabetes," Diabetes, vol. 54, no. 2, pp. 582-586, 2005.

[18] L.-M. Chuang, C. Hsiung, Y.-D. Chen et al., "Sibling-based association study of the PPAR $\gamma 2$ Prol2Ala polymorphism and metabolic variables in Chinese and Japanese hypertension families: A SAPPHIRe study," Journal of Molecular Medicine, vol. 79, no. 11, pp. 656-664, 2001.

[19] X. L. Wang, J. Oosterhof, and N. Duarte, "Peroxisome proliferator-activated receptor $\gamma \mathrm{C} 161 \rightarrow \mathrm{T}$ polymorphism and coronary artery disease," Cardiovascular Research, vol. 44, no. 3, pp. 588-594, 1999.

[20] L. Kalabay, L. Jakab, Z. Prohászka et al., "Human fetuin/ $\alpha 2 H S$ glycoprotein level as a novel indicator of liver cell function and short-term mortality in patients with liver cirrhosis and liver cancer," European Journal of Gastroenterology and Hepatology, vol. 14, no. 4, pp. 389-394, 2002.

[21] D. R. Matthews, J. P. Hosker, A. S. Rudenski, B. A. Naylor, D. F. Treacher, and R. C. Turner, "Homeostasis model assessment: insulin resistance and $\beta$-cell function from fasting plasma glucose and insulin concentrations in man," Diabetologia, vol. 28, no. 7, pp. 412-419, 1985.

[22] K. Vörös, L. Gráf Jr., Z. Prohászka et al., "Serum fetuin-A in metabolic and inflammatory pathways in patients with myocardial infarction," European Journal of Clinical Investigation, vol. 41, no. 7, pp. 703-709, 2011.

[23] A. S. F. Doney, B. Fischer, S. Lee, A. D. Morris, G. P. Leese, and C. N. A. Palmer, "Association of common variation in the PPARA gene with incident myocardial infarction in individuals with 
type 2 diabetes: A Go-DARTS study," Nuclear Receptor, vol. 3, article no. 4, 2005.

[24] J. T. Triffitt, U. Gebauer, B. A. Ashton, M. E. Owen, and J. J. Reynolds, "Origin of plasma $\alpha 2 \mathrm{HS}$-glycoprotein and its accumulation in bone," Nature, vol. 262, no. 5565, pp. 226-227, 1976.

[25] D. Pal, S. Dasgupta, R. Kundu et al., "Fetuin-A acts as an endogenous ligand of TLR4 to promote lipid-induced insulin resistance," Nature Medicine, vol. 18, no. 8, pp. 1279-1285, 2012.

[26] N. Stefan and H.-U. Häring, "Circulating fetuin-A and free fatty acids interact to predict insulin resistance in humans," Nature Medicine, vol. 19, no. 4, pp. 394-395, 2013.

[27] A. S. F. Doney, B. Fischer, J. E. Cecil et al., "Association of the Pro12Ala and C1431T variants of PPARG and their haplotypes with susceptibility to Type 2 diabetes," Diabetologia, vol. 47, no. 3, pp. 555-558, 2004.

[28] Z. Vergotine, Y. Y. Yako, A. P. Kengne, R. T. Erasmus, and T. E. Matsha, "Proliferator-activated receptor gamma Pro12Ala interacts with the insulin receptor substrate 1 Gly972Arg and increase the risk of insulin resistance and diabetes in the mixed ancestry population from South Africa," BMC Genetics, vol. 15, article no. 10, 2014.

[29] A. Motavallian, S. Andalib, G. Vaseghi, H. MirmohammadSadeghi, and M. Amini, "Association between PRO12ALA polymorphism of the PPAR- $\gamma 2$ gene and type 2 diabetes mellitus in Iranian patients," Indian Journal of Human Genetics, vol. 19, no. 2, pp. 239-244, 2013.

[30] X. Wang, J. Liu, Y. Ouyang, M. Fang, H. Gao, and L. Liu, "The association between the Prol2Ala variant in the PPAR $\gamma 2$ gene and type 2 diabetes mellitus and obesity in a Chinese population," PLoS ONE, vol. 8, no. 8, Article ID e71985, 2013.

[31] M. H. Noureldein, R. S. Abd El-Razek, M. H. El-Hefnawy, and H. O. El-Mesallamy, "Fenofibrate reduces inflammation in obese patients with or without type 2 diabetes mellitus via sirtuin 1/fetuin A axis," Diabetes Research and Clinical Practice, vol. 109, no. 3, pp. 513-520, 2015.

[32] A. V. Contreras, N. Torres, and A. R. Tovar, "PPAR- $\alpha$ as a key nutritional and environmental sensor for metabolic adaptation," Advances in Nutrition, vol. 4, no. 4, pp. 439-452, 2013. 


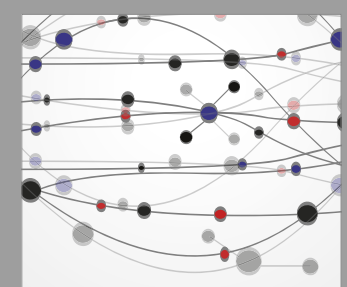

The Scientific World Journal
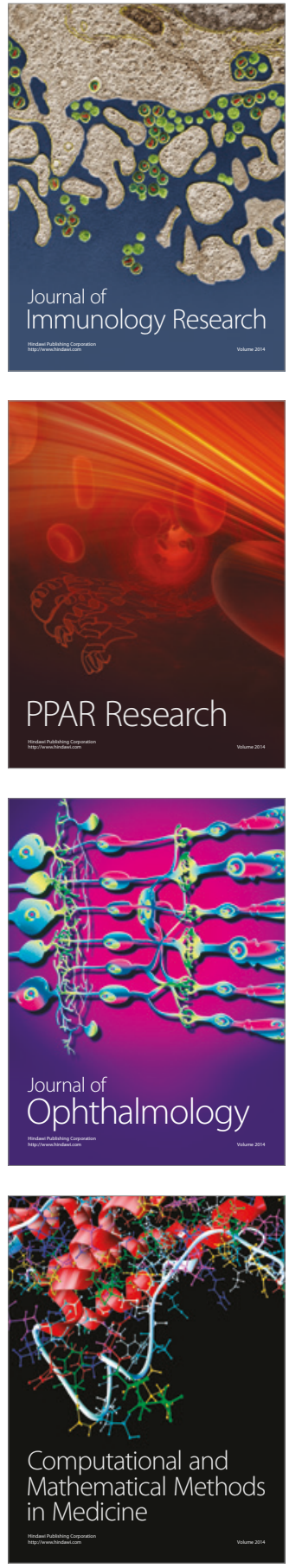

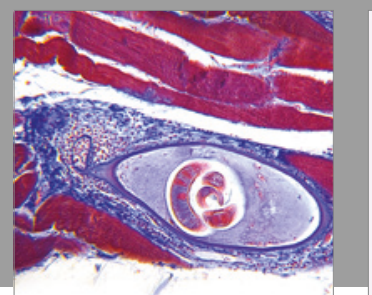

Gastroenterology Research and Practice
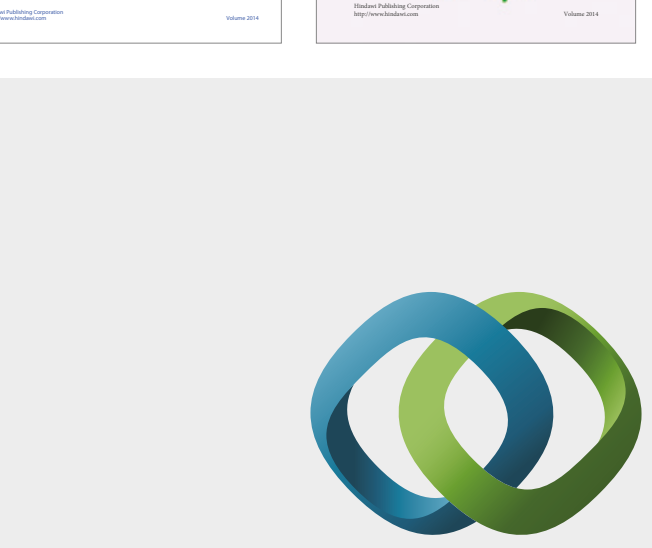

\section{Hindawi}

Submit your manuscripts at

https://www.hindawi.com
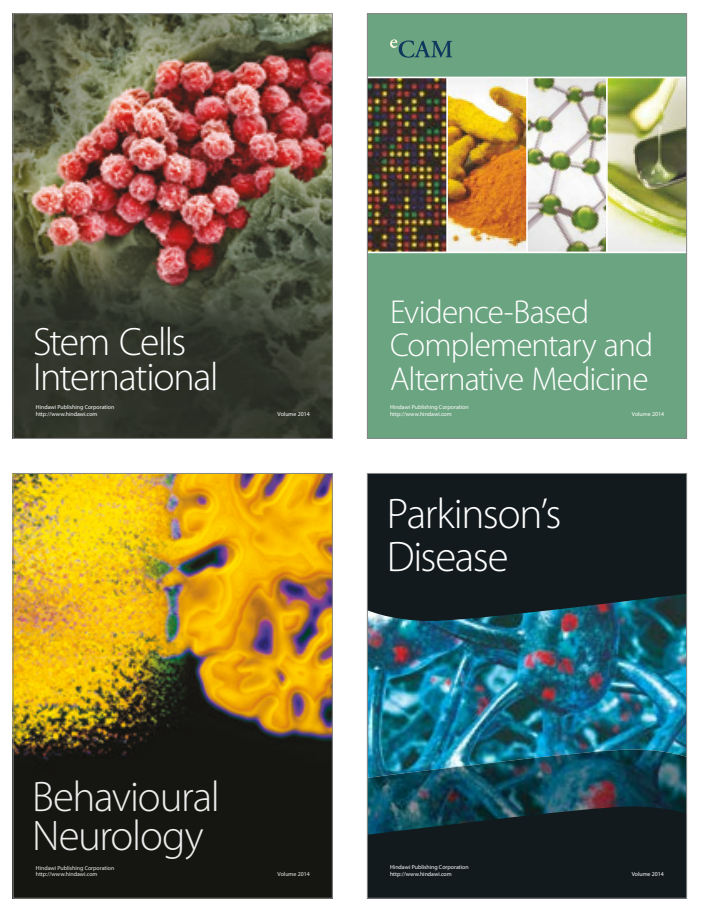
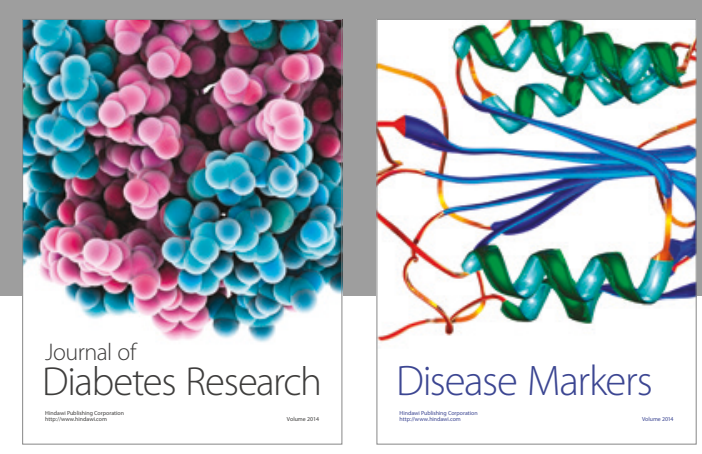

Disease Markers
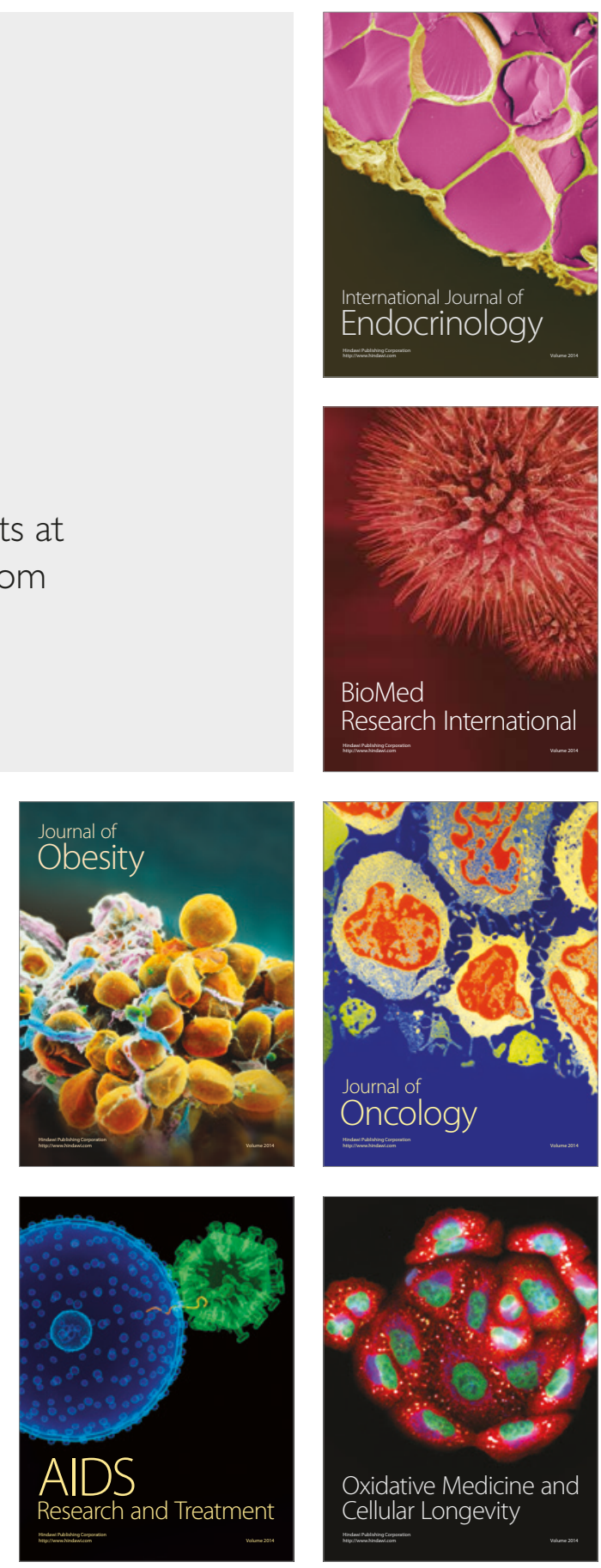